\title{
Performance Study on IEEE Bus System for Contingency Problem and Mitigation
}

\author{
Jayprakash Giri \\ M. Tech Scholar \\ Gyan Ganga Institute of \\ Technology \& Science \\ Jabalpur, M.P., India \\ girijay11@gmail.com
}

\author{
Sh. Rajiv Chauhan \\ HOD, Electrical Engineering \\ Gyan Ganga Institute of \\ Technology \& Science \\ Jabalpur, M.P., India
}

\author{
Smt. Nidhi Mishra \\ Professor \\ Gyan Ganga Institute of \\ Technology \& Science \\ Jabalpur, M.P., India
}

\begin{abstract}
The increasing dependence of most businesses on electricity requires regular improvements in distribution systems. The main objective of this study is to provide load balancing in the distribution network by reducing the loss of system performance without violating the voltage and current limits of the power supplies. And the selection of the power system contingency by calculating the transmission line failure performance indices using the load flow analysis on the IEEE 14 bus system. To determine and tabulate the voltage on each bus, the actual current flow on each line and power system leak for specified bus or terminal conditions. Use of DC studies where stress conditions also vary. In this paper, the selection and classification of potential liabilities, important for the analysis of potential liabilities, was carried out by evaluating two important performance indices, namely the active and reactive power index (PIp \& PIv). The global performance index (OPI) is calculated. It is the sum of two severity indices, namely the real power index and the voltage power index using the direct current flow method. The work was carried out on the bus system 14 and the line between the buses (9-10) was extremely sensitive to the emergency problem of the described system.
\end{abstract}

Keywords: DC, IEEE, Global performance index, Contingency

\section{INTRODUCTION}

The growing dependence on electricity for most of their businesses requires regular improvements in distribution systems. This improvement includes not only increasing the service area and system capacity, but also improving the quality of service and system reliability. Safety assessment plays an important role in power distribution networks as it provides system engineers with a theoretical framework for measuring the quality of energy provided by utility companies and provides a tool to aid decision making in an emergency. Contingency analysis is a key function of security assessment, used to predict and mitigate potential failures in the distribution network. Basically, contingency analysis consists of two phases: the selection of the contingency and the evaluation of the contingency $[1,2]$. In the emergency selection phase, rapid and approximate methods of load flow calculation are usually used in order to speed up the analysis process and select a list of serious contingencies for further evaluation [3] - [7]. In the emergency assessment phase, selected emergency candidates are evaluated through a more detailed analysis to verify violations. Particularly when an electrical grid has severe power or reactive voltage problems, a fast and accurate power flow solution must be used to correct the resulting flows and voltages in the event of a fault. The accuracy of the load modeling has an important influence on the results of the load flow calculation. The load is one of the most important electrical components in the operation and control of the electrical network. Grid planning and operational decisions are based on simulations of the dynamic behavior of the power system. The technical and commercial segments of the industry must be able to rely on the accuracy and updating of the simulation models and the database. Currently, most utility companies treat customer demand as a constant load when analyzing the load flow of secondary power distribution. Significant changes in the nature of the electric charge over the past decade have shown that a more accurate representation of the charge is essential.

\section{LITERATURE REVIEW}

Abdullah M.Al-Shaalan et al. [1] in this paper, a probabilistic document of execution has been made to play out the assurance and plan of potential outcomes. The results show that considering plausibility up to the ensuing level is worthy for both exactness and estimation time requirements.

Kassim A. Al-Anbarri et al. [2] this article presents a computation for orchestrating fundamental scenes in a high voltage association. The technique presented relies upon a mutt 
weighted display document. The Hybrid Performance Index assesses over-trouble transmission lines and transport voltage deviation outside reasonable cutoff focuses. An immediate technique is used to figure the hybrid execution list. The proposed estimation is applied to the IEEE24 transport unfaltering quality test system.

A.P.S. Meliopoulos et al. [3] a possibility request procedure is proposed to perceive pressure issues. The procedure relies upon the AC grid model and a voltage tricky power record. A capable estimation is proposed to register the advancement of the display list in regards to each chance. The procedure considers the effects of: voltage regulators; Discontinuity due to cutoff point's old enough vehicles; Discontinuity due to the difference in the transformer connection cutoff focuses; and voltage subordinate weights.

Namami Krishna Sharma et al. [4] In this article, transmission lines and power plants routinely work at unfaltering quality cutoff points as the store on the power network increases and the system is most likely going to lose its consistent state in view of over-trouble or agitating impact. For the reasons referred to, the assumption and acknowledgment of voltage instability in the electrical association is of explicit importance and grows the security of the association.

\section{OBJECTIVE}

The objective form the contingency analysis shall be focused to achieve the following key end results:

- to provide the load balancing to the distribution network by reducing the power loss of the system without violating the voltage and current limits of the feeders.

- the selection of power system contingencies by calculating the performance indices for transmission line outages using load flow analysis on IEEE 14 bus system.

- The over loaded as well as poor voltages existing in parts of the system has to be detected.

- To determine and tabulate the voltage at each bus, real power flow in each line and line losses in the power system for specified bus or terminal conditions. Using DC power flow studies involving variation in the loading condition as well.

\section{Methodology}

During an emergency situation on the transmission line, the active power flow limit and the reactive power limit are changed, which particularly affects the bus voltage. It is therefore important to predict this power flow and bus voltages after an eventuality. This study is primarily concerned with the different modeling methods used in contingency analysis. Contingency analysis using sensitivity factors was discussed. In addition, the use of alternating current for contingency analysis was presented in detail. The contingency analysis algorithm using fast decoupled load flow was developed with emphasis on implementing contingency selection for line contingencies for various test bus systems discussed in detail.

\section{A. IEEE 14 Bus System}

IEEE transport frameworks are used by analysts to implement new thoughts and ideas. This particular note shows the complexities of the IEEE 14 transport framework [1]. The structure consists of loads, capacitor banks, transmission lines and generators.

A. Bus Classification Ultimately, a bus is held in a power frame by generators, which allow dynamic and reactive force to flow through it and load actual and absorbable forces in load current considerations. The forces of the generator and the load (complex forces) become too summed into a net force. This net force is called the wet carrying force. The net force introduced during transport is given by,

$\mathrm{S}=\mathrm{P}+\mathrm{jQ}=\mathrm{P}_{\mathrm{G}}+\mathrm{JQ}_{\mathrm{G}}-\mathrm{P}_{\mathrm{D}}+\mathrm{JQ}_{\mathrm{D}}$

1) Load Bus: The generators are not connected to this bus. The dynamics and the absorption force are displayed on this bus. It is ideal for determining the amplitude and the point of passage of the voltage through a study of the load current. PD and QD interest should indicate on a bus of this type and this bus voltage can vary within the appropriate classes. 5\%. Also, the bus voltage crossing point is not critical to the heap.

2) Generator Bus or Voltage Controlled Bus: The generator bus voltage bus is a bus where the voltage amplitude is determined in terms of age voltage and dynamic strength. It is necessary to determine the HQ and the point of no voltage.

3) Slack (Swing) Bus: This type of bus differs from other buses in that the dynamics and reception power are not displayed on this bus, but the voltage and step point are referred to. In a given context, there is usually only one bus.

First, dynamic power and receive power are not displayed for all buses, so the jumbled power flow in the frame is not known. The lack of performance is also obscure until the power scheme is completed. Consequently, it is important to have a bus on which complex execution is not committed to counteract full framework load and bad luck. Therefore, it should be a bus generator.

\section{B. Contingency Ranking Approach}


Since Opportunity Investigation involves replicating every possibility using the Base Force Framework case model, this investigation faces three fundamental challenges. The first is the difficulty of building the appropriate electric scaffolding model. There is also the crisis decision to consider and thirdly the difficulty of determining the bus current and voltages, which leads to an immense use of time in the board frame energy.

In this way, the exploration of online opportunities should be divided into three unique stages, in particular the identification, selection and evaluation of opportunities. The meaning of possibility includes the arrangement of potential possibilities that can arise in an electrical environment. The list of options is created during the interaction. The choice of the unexpected is a cycle in which the most genuine unexpected responsibilities are distinguished from the summary of the unexpected responsibilities, thus limiting the interruption and the magnitude of the bus voltage. This cycle then eliminates the less real contingent liabilities and shortens the overview of unexpected liabilities. Saved estimates are used to demonstrate the severity of unforeseen liabilities. Crises are sorted by the consequences of these record estimates. A crisis assessment is then performed, which includes welfare measures or controls that are important to reduce the impact of the possibility.

A feasibility study using direct current has the advantage that the current currents are specified up to the measurement of the MW and bus voltage. Using more accurate DC current overloads and violation of the voltage limit. In the work in progress, the disappointments of each line have been taken into account for the order of possibilities. The execution lists (PIs) are classified as the severity of a specific inevitability. Common power flow strategies are used to map files in detached mode. Upon receipt, the qualities acquired through the normal strategy are organized in a scrollable query and the most notable PI value is placed first.

There are two types of performance indices [9] which are mainly used for emergency analysis:

Active Power performance index $\left(\mathrm{PI}_{\mathrm{P}}\right)$ : This is the index which helps in determining theextent of line over loads.

$$
P I_{P}=\sum_{l}^{N_{L}}\left(\frac{W}{2 n}\right)\left(\frac{P_{l}}{P_{l}^{\text {max }}}\right)^{2 n}
$$

$\mathrm{N}_{\mathrm{L}}$ is the number of lines of the system $\mathrm{W}$ is the real nonnegative weighting factor, and value is $(=1) \mathrm{n}$ is exponent of penalty function and value is $(=1)$

$$
P_{l}^{\max }=\left(V_{i} * V_{j}\right) / X
$$

Where,
$\mathrm{V}_{\mathrm{i}}$ is the voltage at bus $i^{\text {th }}$ obtained from the DC power flow solution

$\mathrm{V}_{\mathrm{j}}$ is the voltage at bus $\mathrm{j}^{\text {th }}$ obtained from the DC power flow solution

$\mathrm{X}$ is the reactance of the line connecting $i^{\text {th }}$ bus and $\mathrm{j}^{\mathrm{th}}$

Voltage performance index (PIV): This is the index which helps in determining busvoltages limit violation.

$$
P I_{V}=\sum_{i=1}^{N_{B}}\left(\frac{W}{2 n}\right)\left(\frac{\left|V_{i}\right|-\left|V_{i}^{s p}\right|}{V_{i}^{l i m}}\right)^{2 n}
$$

Where,

$\left|V_{i}\right|$ is the voltage magnitude at $i^{\text {th }}$ bus.

$\left|\mathrm{V}_{\mathrm{i}}^{\mathrm{sp}}\right|$ is the specified (rated) voltage magnitude at $i^{\text {th }}$ bus.

$V_{i}^{\text {lim }}$ is the deviation limit of the voltage.

$\mathrm{n}$ is the exponent of penalty function and value is $(=1)$

$\mathrm{N}_{B}$ is the number of buses in the system taken.

$\mathrm{W}$ the real non-negative weighting factor and the value is $(=1)$ The bus voltages are further affected by the reaction force generated by the gensets and PIV provides data on the severity of the strange voltages as long as the absorption force is not in the limit points or not. In a crisis and when the absorption force reaches its limit points and the limit values of the reaction force are observed under these conditions, the standard AC load current determines the bus voltages and in this way there is a voltage deviation from the its normal tension on the generator bus. In this way, the ability to test the voltage also includes limiting the reaction force of the generators.

The generalized formula is represented by eqn. :

$$
O P I=\sum_{l}^{N_{L}}\left(\frac{W}{2 n}\right)\left(\frac{P_{l}}{P_{l}^{\max }}\right)^{2 n}+\sum_{i=1}^{N_{B}}\left(\frac{W}{2 n}\right)\left(\frac{\left|V_{i}\right|-\left|V_{i}^{s p}\right|}{V_{i}^{l i m}}\right)^{2 n}
$$

Where,

$\mathrm{Q}_{\mathrm{i}}$ is the produced reactive power at ith bus $\mathrm{Q}_{\mathrm{i}}{ }^{\max }$ is the reactive power production limit.

$\mathrm{N}_{\mathrm{G}}$ is the number of generating units in the system.

$\mathrm{W}$ is the real non-negative weighting factor and its value is (= 1)

\section{Algorithm for Contingency Analysis}

The proposed approach for contingency ranking is shown in flow chart (Fig.)

The step by step implementation of the algorithm for contingency analysis is as follows:

Step 1: Read the given system's line data and bus data. 
Step 2: Without considering the line contingency perform the load flow analysis for base case.

Step 3: Simulating a line outage or line contingency, i.e. removing a line and proceeding to the next step.

Step 4: Load flow analysis is done for this particular outage, then calculation of the active power flow is done in the remaining lines and value Pmax is found out.

Step 5: The active power performance index $\left(\mathrm{PI}_{\mathrm{P}}\right)$ is found, which indicates the active power limit violation of the system model taken.

Step 6: subsequently for the particular line contingency; voltages of all the load buses are calculated.

Step 7: Then voltage performance index $\left(\mathrm{PI}_{\mathrm{V}}\right)$ is being calculated which indicates the voltage limit violation at all the load buses due to the line contingencies.

Step 8: Computation of overall performance index is done by adding $\mathrm{PI}_{\mathrm{P}}$ and $\mathrm{PI}_{\mathrm{V}}$ for each line outage of the system.

Step 9: Steps 3 to 8 for all line outages is repeated to obtain the $\mathrm{PI}_{\mathrm{P}}$ and $\mathrm{PI}_{\mathrm{V}}$. For all line outages.

Step 10: Then contingencies is ranked based on the overall performance index (OPI) which is calculated according to the values of the performance indices obtained.

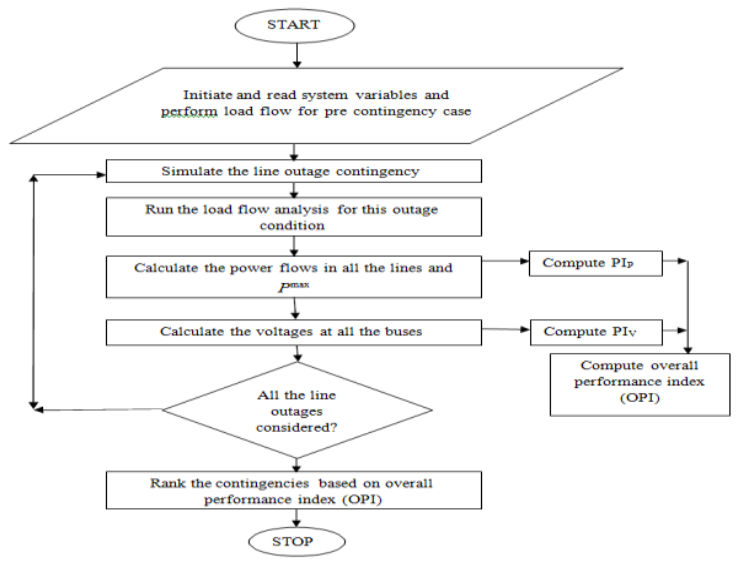

Fig. 1 Flow chart of contingency study

\section{RESUlts}

\section{A. Implementation Details}

This study provides an analytical and numerical description of the proposed algorithm for sentiment analysis of a performance buffer that is simulated to maintain the performance of the proposed algorithm.
To evaluate the performance of the proposed algorithm scheme, the proposed algorithm is simulated in the following configuration:

Pentium Core I5-2430M CPU @ 2.40 GHz

\section{GB RAM}

64-bit Operating System

\section{MATLAB Platform}

\section{B. Simulation Environment}

MATLAB stands for MATrix LABoratory, a programming software package developed exclusively for quick and easy logic calculations and input / output. It has hundreds of built-in functions for a wide variety of calculations and many toolkits for specific analysis disciplines, as well as information on statistics, optimization, solving partial differential equations, and analysis.

In this research report, the MATLAB platform is used to show the implementation or performance simulation of the implemented algorithm. Measurement toolkits and some built-in functions are used to generate graphs. The results of the simulation of the performance of the bus system implemented with certain algorithms are calculated by the MATLAB functions.

The main objective here is to carry out the contingency selection process by calculating the active power indices and reactive power indices, for example H.PIP or PIV. Contingent liabilities are then classified and the most serious contingent liability is the one with the highest performance index. These indices were calculated based on a load flow analysis, performed using power flow analysis in a MATLAB environment. The most severe contingency is then selected from the contingency list and the corresponding power flows and bus voltages are analyzed for the entire system.

The IEEE-14 bus system shown in Figure 2 consists of a Slack bus, 9 load buses, and 3 generator buses. There are three synchronous compensators which are used only for reactive power compensation. In Fig. The line and bus data of the IEEE 14 bus system are shown in tables 1 and 2 .

Table 1: Line data - IEEE 14 bus system

\begin{tabular}{|c|c|c|c|c|c|c|}
\hline \multirow{2}{*}{$\begin{array}{l}\text { Line } \\
\text { numbe }\end{array}$} & \multirow{2}{*}{$\begin{array}{l}\text { Fro } \\
\text { m } \\
\text { bus }\end{array}$} & \multirow{2}{*}{$\begin{array}{l}\text { To } \\
\text { bus }\end{array}$} & \multicolumn{2}{|c|}{$\begin{array}{l}\text { Line impedance } \\
(\text { p.u. })\end{array}$} & \multirow{2}{*}{$\begin{array}{l}\text { Half line } \\
\text { charging } \\
\text { susceptance } \\
\text { (p.и.) }\end{array}$} & \multirow{2}{*}{$\begin{array}{l}\text { MVA } \\
\text { rating }\end{array}$} \\
\hline & & & Resistanc & $\begin{array}{l}\text { Reactan } \\
\text { ce }\end{array}$ & & \\
\hline 1 & 1 & 2 & 0.01938 & 0.05917 & 0.02640 & 120 \\
\hline
\end{tabular}




\begin{tabular}{|c|c|c|c|c|c|c|}
\hline 2 & 1 & 5 & 0.05403 & 0.22304 & 0.02190 & 65 \\
\hline 3 & 2 & 3 & 0.04699 & 0.19797 & 0.01870 & 36 \\
\hline 4 & 2 & 4 & 0.05811 & 0.17632 & 0.02460 & 65 \\
\hline 5 & 2 & 5 & 0.05695 & 0.17388 & 0.01700 & 50 \\
\hline 6 & 3 & 4 & 0.06701 & 0.17103 & 0.01730 & 65 \\
\hline 7 & 4 & 5 & 0.01335 & 0.04211 & 0.00640 & 45 \\
\hline 8 & 4 & 7 & 0 & 0.20912 & 0 & 55 \\
\hline 9 & 4 & 9 & 0 & 0.55618 & 0 & 32 \\
\hline 10 & 5 & 6 & 0 & 0.25202 & 0 & 45 \\
\hline 11 & 6 & 11 & 0.09498 & 0.1989 & 0 & 18 \\
\hline 12 & 6 & 12 & 0.12291 & 0.25581 & 0 & 32 \\
\hline 13 & 6 & 13 & 0.06615 & 0.13027 & 0 & 32 \\
\hline 14 & 7 & 8 & 0 & 0.17615 & 0 & 32 \\
\hline 15 & 7 & 9 & 0 & 0.11001 & 0 & 32 \\
\hline 16 & 9 & 10 & 0.03181 & 0.0845 & 0 & 32 \\
\hline 17 & 9 & 14 & 0.12711 & 0.27038 & 0 & 32 \\
\hline 18 & 10 & 11 & 0.08205 & 0.19207 & 0 & 12 \\
\hline 19 & 12 & 13 & 0.22092 & 0.19988 & 0 & 12 \\
\hline 20 & 13 & 14 & 0.17093 & 0.34802 & 0 & 12 \\
\hline
\end{tabular}

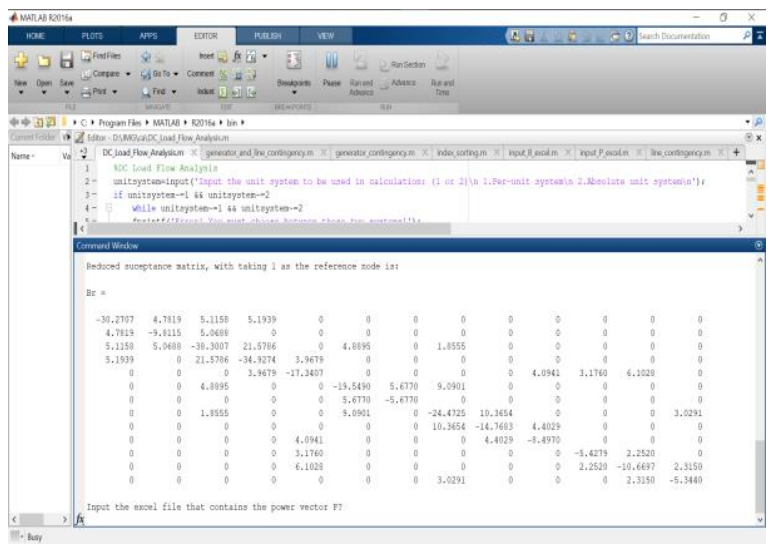

Fig. 2. Reduced suceptance matrix, with taking bus 1 as the reference bus

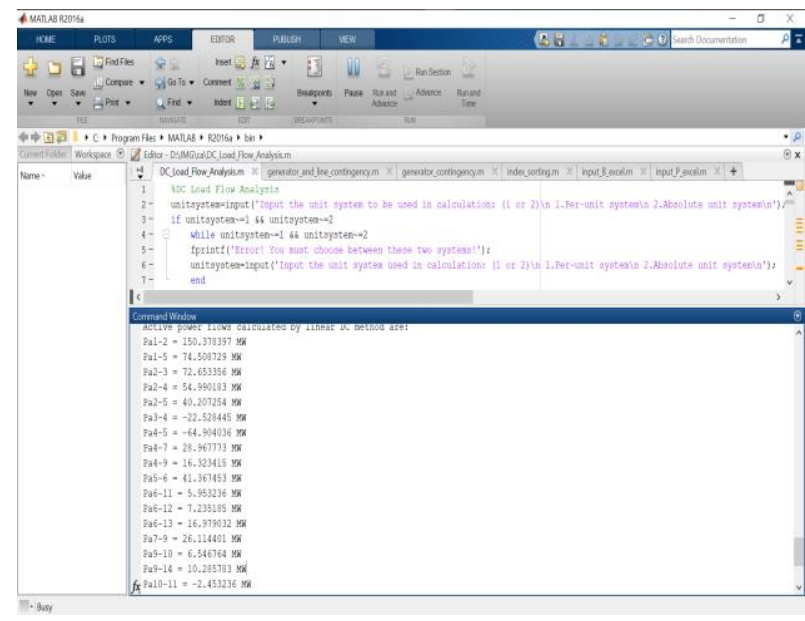

Fig. 3. Pre contingency power flow in different lines

The system has a total of 20 transmission lines. For this reason, we are evaluating 20 line emergency scenarios, each taking into account the possibility of a line failure. The performance indices are summarized in Table 3. From Table 2 it can be inferred that the error in row 16 is the most sensitive and has a significant impact on the entire system. The high PIV value for this fault also suggests that this line receives the most attention during operation. Figure 4. Shows the graphical representation of the performance indices for all row dimensions with the PI value on the $\mathrm{y}$ axis and the error row number on the $\mathrm{x}$ axis.

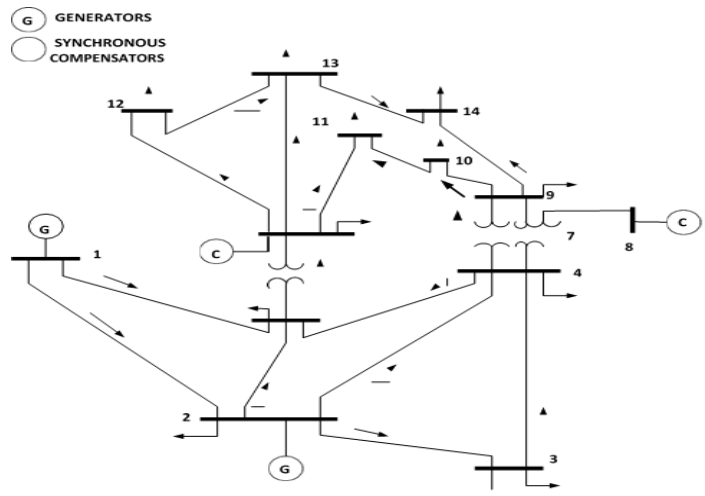

Fig. 4 IEEE 14-Bus System for contingency

Table 2 Bus data - IEEE 14 bus system

\begin{tabular}{|c|c|c|c|c|c|c|c|c|c|c|}
\hline \multirow{2}{*}{$\begin{array}{l}\text { Bus } \\
\text { No. }\end{array}$} & \multirow{2}{*}{$\begin{array}{l}\text { Bus } \\
\text { Cod } \\
\text { e }\end{array}$} & \multirow{2}{*}{$\begin{array}{l}\text { Voltage } \\
\text { Magnitu } \\
\text { de }\end{array}$} & \multirow{2}{*}{\begin{tabular}{|l} 
Angle \\
Degre \\
es
\end{tabular}} & \multicolumn{2}{|l|}{ Load } & \multicolumn{4}{|c|}{ Generator } & \multirow{2}{*}{$\begin{array}{l}\text { Injecte } \\
\mathrm{d} \\
\mathrm{MVA} \\
\mathrm{R}\end{array}$} \\
\hline & & & & MW & $\begin{array}{l}\text { MVA } \\
\mathrm{R}\end{array}$ & $\begin{array}{l}\mathrm{M} \\
\mathrm{W}\end{array}$ & $\begin{array}{l}\mathrm{MV} / \\
\mathrm{R}\end{array}$ & $\begin{array}{l}\mathrm{Qmi} \\
\mathrm{n}\end{array}$ & $\begin{array}{l}\text { Qma } \\
\mathrm{x}\end{array}$ & \\
\hline 1 & 1 & 1.06 & 0 & 30.38 & 17.78 & 40 & -40 & 0 & 0 & 0 \\
\hline 2 & 2 & 1.045 & 0 & 0 & 0 & 232 & 0 & -40 & 50 & 0 \\
\hline 3 & 2 & 1.01 & 0 & $\begin{array}{l}131.8 \\
8\end{array}$ & 26.6 & 0 & 0 & 0 & 40 & 0 \\
\hline 4 & 0 & 1 & 0 & 66.92 & 10 & 0 & 0 & 0 & 0 & 0 \\
\hline
\end{tabular}




\begin{tabular}{|l|l|l|l|l|l|l|l|l|l|l|}
\hline 5 & 0 & 1 & 0 & 10.64 & 2.24 & 0 & 0 & 0 & 0 & 0 \\
\hline 6 & 2 & 1.07 & 0 & 15.68 & 10.5 & 0 & 0 & -6 & 24 & 0 \\
\hline 7 & 0 & 1 & 0 & 0 & 0 & 0 & 0 & 0 & 0 & 0 \\
\hline 8 & 2 & 1.09 & 0 & 0 & 0 & 0 & 0 & -6 & 24 & 0 \\
\hline 9 & 0 & 1 & 0 & 41.3 & 23.24 & 0 & 0 & 0 & 0 & 0 \\
\hline 10 & 0 & 1 & 0 & 12.6 & 8.12 & 0 & 0 & 0 & 0 & 0 \\
\hline 11 & 0 & 1 & 0 & 4.9 & 2.52 & 0 & 0 & 0 & 0 & 0 \\
\hline 12 & 0 & 1 & 0 & 8.54 & 2.24 & 0 & 0 & 0 & 0 & 0 \\
\hline 13 & 0 & 1 & 0 & 18.9 & 8.12 & 0 & 0 & 0 & 0 & 0 \\
\hline 14 & 0 & 1 & 0 & 20.86 & 7 & 0 & 0 & 0 & 0 & 0 \\
\hline
\end{tabular}

Table 3 Performance Indices \& Contingency Ranking using DCLF for 14-Bus System

\begin{tabular}{|c|c|c|c|c|}
\hline $\begin{array}{l}\text { Outage of the } \\
\text { line }\end{array}$ & $\mathrm{PI}_{\mathrm{P}}$ & $\mathrm{PI}_{V}$ & OPI & Ranking \\
\hline 1 & 1.2593 & 7.3032 & 8.5625 & 11 \\
\hline 2 & 1.0807 & 8.0006 & 9.0813 & 10 \\
\hline 3 & 1.2004 & 10.0014 & 11.2018 & 7 \\
\hline 4 & 1 & 7.3213 & 8.3213 & 12 \\
\hline 5 & 1.072 & 9.0059 & 10.0779 & 9 \\
\hline 6 & 0.954 & 13.2572 & 14.2112 & 2 \\
\hline 7 & 1.005 & 0.3566 & 1.3616 & 19 \\
\hline 8 & 1.1007 & 1.1753 & 2.276 & 18 \\
\hline 9 & 0.9607 & 11.0076 & 11.9683 & 4 \\
\hline 10 & 1.2396 & 2.0047 & 3.2443 & 15 \\
\hline 11 & 1.0142 & 10.0007 & 11.0149 & 8 \\
\hline 12 & 1.0127 & 2.0089 & 3.0216 & 16 \\
\hline 13 & 1.1009 & 1.3669 & 2.4678 & 17 \\
\hline 14 & 1.0072 & 10.4518 & 11.459 & 6 \\
\hline 15 & 1.1059 & 0.1044 & 1.2103 & 20 \\
\hline 16 & 1.0114 & 13.3464 & 14.3578 & 1 \\
\hline 17 & 1.0164 & 2.3482 & 3.3646 & 13 \\
\hline 18 & 1.003 & 10.5217 & 11.5247 & 5 \\
\hline 19 & 1.0008 & 12.5538 & 13.5546 & 3 \\
\hline 20 & 1.0076 & 2.2891 & 3.2967 & 14 \\
\hline
\end{tabular}

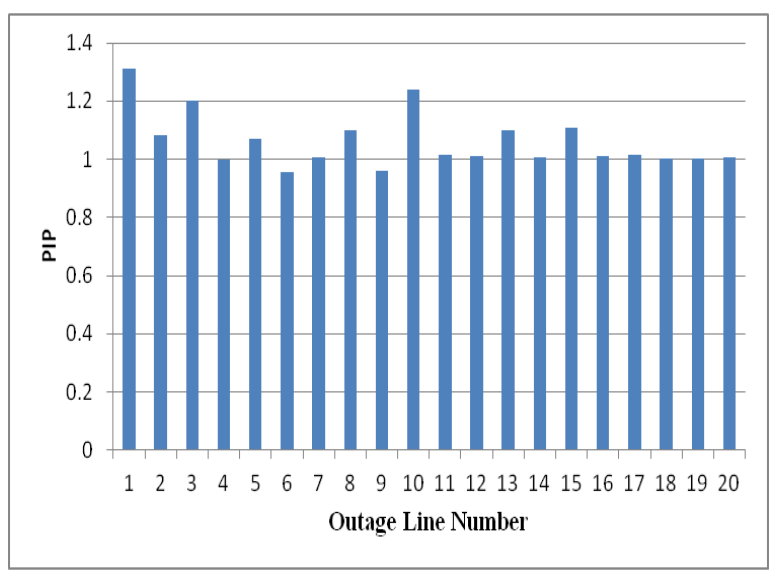

Fig. 5. PIP for 14-Bus system

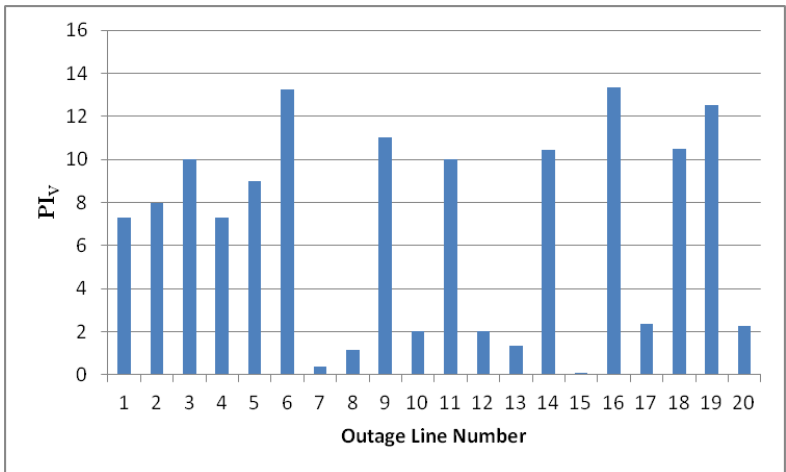

Fig. 6 B Values of PIV for 14-Bus system

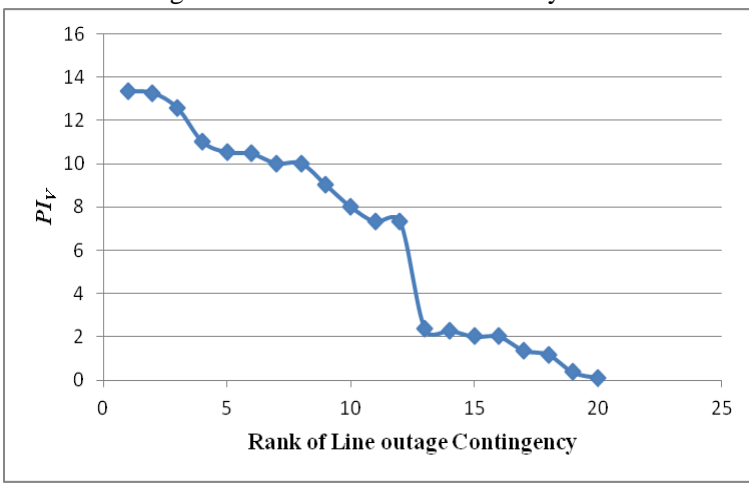

Fig. 7 C Contingency Ranking and PIV of 14-Bus system 


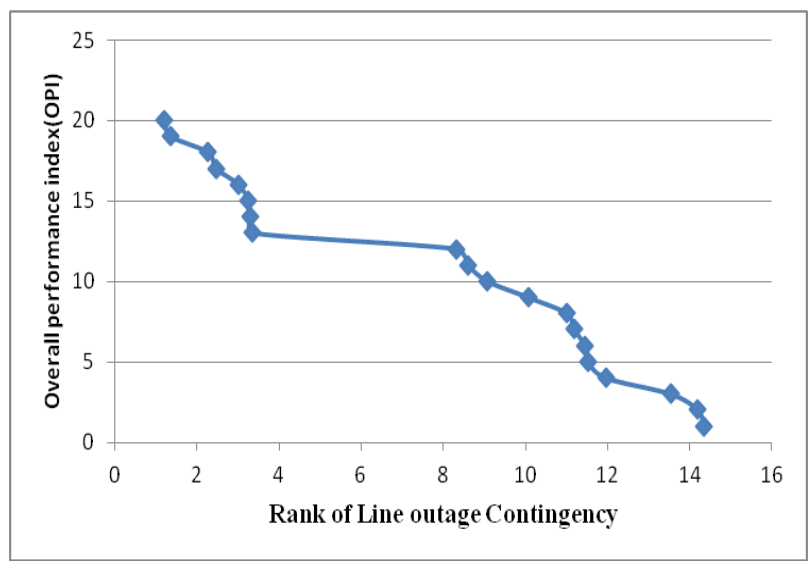

Fig. 8 D Contingency Ranking and OPI of 14-Bus system

Contingent liabilities were ranked with the most serious contingent liability in first place and the lowest in 20th place. The variation of the reactive power index with its classification is illustrated in figure $\mathrm{C}$. The result of the different PIV leads to quota number 16, for which the quota corresponds to the line connected between the buses (9) in case of failure line -10) is the most serious contingent. A post-contingency analysis corresponding to this line break was then performed. The system voltage, which corresponds to the state before and after the contingency, is shown in Table 4. The MW fluxes corresponding to the state before and after the contingency are listed in table $\mathrm{w}$ and in table 4 for the ranks. Contingency 1 and 2 respectively.

Table 4 Bus Voltages in the Pre and Post Contingency State

\begin{tabular}{|c|l|l|}
\hline Bus Number & $\begin{array}{l}\text { Pre-contingency } \\
\text { voltage } \\
(\mathrm{pu})\end{array}$ & $\begin{array}{l}\text { Post-contingency } \\
\text { voltage } \\
(\mathrm{pu})\end{array}$ \\
\hline 1 & 1.075 & 1.075 \\
\hline 2 & 1.050 & 1.050 \\
\hline 3 & 1.000 & 1.000 \\
\hline 4 & 1.002 & 1.000 \\
\hline 5 & 1.009 & 1.009 \\
\hline 6 & 1.025 & 1.025 \\
\hline 7 & 1.007 & 1.008 \\
\hline 8 & 1.016 & 0.996 \\
\hline 9 & 0.993 & 0.978 \\
\hline 10 & 0.991 & 0.997 \\
\hline 11 & 1.004 & 1.008 \\
\hline 12 & 1.007 & 1.002 \\
\hline 13 & 1.001 & 0.980 \\
\hline 14 & 0.978 & Post \\
\hline
\end{tabular}

Table $5 \mathrm{~W}$ Active Power Flow in the Pre and Post Contingency State

\begin{tabular}{|c|c|c|c|c|}
\hline $\begin{array}{l}\text { Line } \\
\text { No }\end{array}$ & $\begin{array}{l}\text { Start } \\
\text { Bus }\end{array}$ & $\begin{array}{l}\text { End } \\
\text { Bus }\end{array}$ & $\begin{array}{l}\text { Pre } \\
\text { contingency } \\
\text { MW flow }\end{array}$ & $\begin{array}{l}\text { Post contingency } \\
\text { MW flow }\end{array}$ \\
\hline 1 & 1 & 2 & 150.378397 & 150.1399 \\
\hline 2 & 1 & 5 & 74.508729 & 74.77941 \\
\hline 3 & 2 & 3 & 72.653356 & 72.44137 \\
\hline 4 & 2 & 4 & 54.990183 & 54.55181 \\
\hline 5 & 2 & 5 & 40.20725 & 40.6204 \\
\hline 6 & 3 & 4 & 22.528445 & 22.73808 \\
\hline 7 & 4 & 5 & 64.904036 & 61.33853 \\
\hline 8 & 4 & 7 & 28.967773 & 26.3114 \\
\hline 9 & 4 & 9 & 16.323415 & 14.78729 \\
\hline 10 & 5 & 6 & 41.367453 & 45.61372 \\
\hline 11 & 6 & 11 & 5.953236 & 12.5 \\
\hline 12 & 6 & 12 & 7.235185 & 6.826679 \\
\hline 13 & 6 & 13 & 16.979032 & 15.08704 \\
\hline 14 & 7 & 8 & 0 & 0 \\
\hline 15 & 7 & 9 & 26.114401 & 23.52737 \\
\hline 16 & 9 & 10 & 6.546764 & 0 \\
\hline 17 & 9 & 14 & 10.285783 & 12.58629 \\
\hline 18 & 10 & 11 & 2.453236 & 9 \\
\hline 19 & 12 & 13 & 1.135185 & 0.726679 \\
\hline 20 & 13 & 14 & 4.614217 & 2.313715 \\
\hline
\end{tabular}

Table 6 Active Power Flow in the Pre and Post Contingency State

\begin{tabular}{|c|c|c|c|c|}
\hline $\begin{array}{l}\text { Line } \\
\text { No }\end{array}$ & $\begin{array}{l}\text { Start } \\
\text { Bus }\end{array}$ & $\begin{array}{l}\text { End } \\
\text { Bus }\end{array}$ & $\begin{array}{l}\text { Pre } \\
\text { contingency } \\
\text { MW flow }\end{array}$ & $\begin{array}{l}\text { Post } \\
\text { contingency } \\
\text { MW flow }\end{array}$ \\
\hline 1 & 1 & 2 & 150.378397 & 155.1402 \\
\hline 2 & 1 & 5 & 74.508729 & 69.59307 \\
\hline 3 & 2 & 3 & 72.653356 & 95.38034 \\
\hline 4 & 2 & 4 & 54.990183 & 44.64792 \\
\hline 5 & 2 & 5 & 40.20725 & 32.55812 \\
\hline 6 & 3 & 4 & 22.528445 & 0 \\
\hline 7 & 4 & 5 & 64.904036 & 53.05939 \\
\hline 8 & 4 & 7 & 28.967773 & 29.38493 \\
\hline 9 & 4 & 9 & 16.323415 & 16.60254 \\
\hline
\end{tabular}




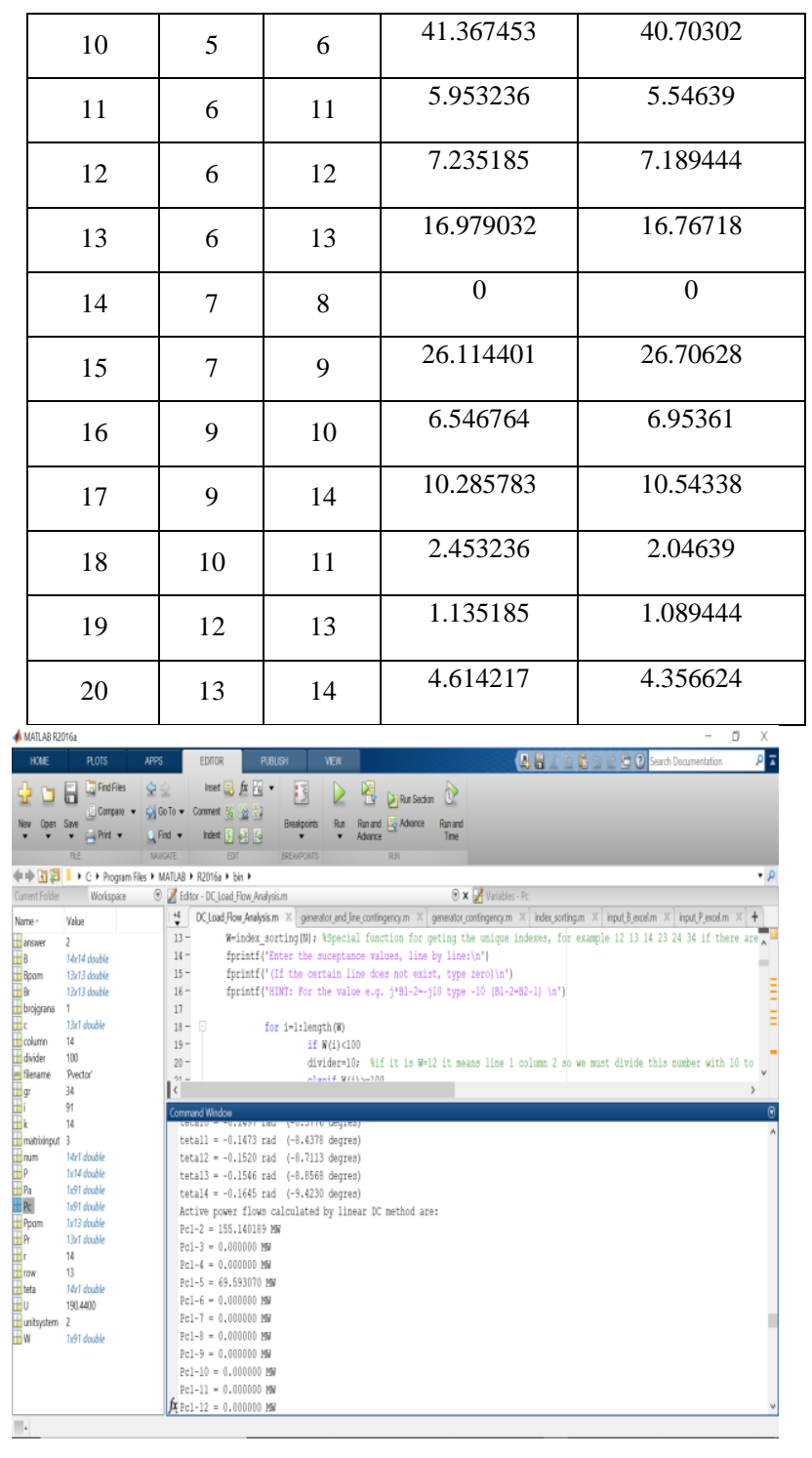

Fig. 9 Rank 2 Contingency power flow

\section{CONCLUSION}

From the results obtained, it can be concluded that the calculation of performance indices is a good measure of the severity of all possible row contingents occurring in the system. The indexes with the highest value reflect a severe case where there is the greatest chance of exceeding the system parameter limits. The most serious emergency situation was then selected from the list of different line contingencies and the associated contingency analysis was performed, based on which the most important system parameters such as voltages and flow rates were performed. The list of potential liability severity levels prior to commissioning the electrical system is a useful guide to the operation of a reliable system.
In this thesis, the selection and classification of potential liabilities, important for the analysis of potential liabilities, was carried out by evaluating two important performance indices, namely the active and reactive power index (PIp \& PIv). The global performance index (OPI) is calculated. It is the sum of two severity indices, namely the real power index and the voltage power index using the direct current flow method. The works were carried out on the bus network 14 and the line between the buses (9-10) was extremely sensitive to the problem of contingency in the system described.

In this way the plant technicians can take the necessary and preparatory measures to solve the problem and thus guarantee a safe, reliable and continuous power supply to the electrical system.

\section{SCOPE FOR FUTURE WORK}

The following can be used for further investigation and analysis: This forecasting technique can be further implemented for superior bus systems, and the forecasting technique can be extended to other software and software calculation techniques.

\section{REFERENCES}

[1] Abdullah M.Al-Shaalan "Contingency selection and ranking for composite power system reliability evaluation", Journal of King Saud University - Engineering Sciences, Volume 32, Issue 2, February 2020, Pages 141-147.

[2] Kassim A. Al-Anbarri, "An approach for contingency ranking analysis of electrical power system”, IOP Conf. Series: Materials Science and Engineering 928 (2020) 022133.

[3] A.P.S. Meliopoulos, C. Cheng "A new contingency ranking method (power systems)", IEEE, Proceedings. IEEE Energy and Information Technologies in the Southeast', 2018.

[4] Namami Krishna Sharma, Sudhir P. Phulambrikar "Contingency Ranking and Analysis using Power System Analysis Toolbox (PSAT)", Innovative Systems Design and Engineering, Vol.4, No.6, 2013 - Selected from International Conference on Recent Trends in Applied Sciences with Engineering Applications.

[5] Swaroop N S, Lekshmi M "Contingency Analysis And Ranking On 400 Kv Karnataka Network By Using Mipower”, October 2016 IJSDR | Volume 1, Issue 10.

[6] Ming Chen, "Contingency Redefinition and its Application to Power System Security Analysis", IEEE Conference on Power Systems Conference and Exposition, 2011, pp. 1-4.

[7] Zhenyu Huang, et. al., "Massive Contingency Analysis with High Performance Computing", IEEE Conference on Power and Energy Society General Meeting, 2009, pp. 1-8.

[8] D.P. Anuradha, J. Rajamohan "Power system contingency ranking using compensation factor in performance index", January 2015 International Journal of Applied Engineering Research 10(3):6807-6816. 
[9] Prem Prakash, Rekha Jha "Contingency Ranking for Power System Using Multilayer Feed Forward Neural Network", ijarse, vol. 6, issue 8, august 2017.

[10] M. Simab, S. Chatrsimab "Using integrated method to rank the power system contingency”, Scientia Iranica D (2017) 24(3), $1373\{1383$. 